\title{
Personality and sensation seeking in high-risk sports
}

\author{
Polona Klinar, Stojan Burnik, and Tanja Kajtna* \\ Faculty of Sport, University of Ljubljana, Ljubljana, Slovenia
}

Copyright: (C) 2017 P. Klinar et al. This is an open access article licensed under the Creative Commons Attribution License (http://creativecommons.org/licenses/by/4.0/).

\begin{abstract}
Background: Personality represents a relatively consistent and unique sum of psychological, cognitive and physical characteristics of an individual. Sensation seeking is defined as an action, characterized by the search for different, new, complex and intensive emotions and experiences and preparedness to take physical, social, legal and financial risks in order to achieve these experiences. Objective: We were looking for differences in personality and sensation seeking between high-risk sports athletes and recreational athletes and the correlation between one's purpose to participate in high-risk sports and actual participation. Method: The data was acquired using three different questionnaires: Sensation Seeking Scale (forms SSS - V and SSS - VI) and the Big Five Questionnaire. The sample consisted of 76 high-risk sports athletes and 51 recreational athletes. Data was analyzed using the SPSS statistical program. Results: The results were unexpected because we noticed differences between the two groups in which recreational athletes received higher results, especially in openness. Mostly results from such research show the converse - athletes of high-risk sports are more open. We did not find any difference between the two groups in sensation seeking. We found some correlations between personality traits and factors of Sensation Seeking Scale (SSS - V and SSS - VI). Openness and the Thrill and adventure seeking factor correlated in both versions of SSS. Conclusions: We conclude that high-risk sports athletes differ from recreational athletes, especially in openness. Also, we can confirm that both used versions of SSS are equally effective for analyzing sensation seeking.
\end{abstract}

Keywords: high-risk sports, personality, sensation seeking, Zuckerman scales

\section{Introduction}

For a certain number of years there has been an increase in interest in physical activities most often called as high-risk or extreme sports, which are activities which offer unusual and intense sensations. They are defined as sports, which require extra original skills, courage and the ability to act in situations where a person's life is endangered (Guszkowska \& Bołdak, 2010). Alpinism, extreme kayaking, diving, ski jumping, sky diving, downhill skiing, mountain biking, snowboarding are just some sports we could define as high-risk (Kajtna, 2013). These sports to some extent converge with sports, which are often called "action sports" (Thorpe \& Wheaton, 2013), are not necessarily the same. These sports mainly stem from rebelling against the social norm and often include a dimension of subculture (Rinehart, 2000), but in our case we are focusing

\footnotetext{
* Address for correspondence: Tanja Kajtna, Department of Sports Training, Faculty of Sport, University of Ljubljana, Gortanova 22, 1000 Ljubljana, Slovenia. E-mail: tanja.kajtna@fsp.uni-lj.si
}

mainly on the hazardous nature of these sports, as they include exposure to physical danger, more in line with Barrett and Martin's (2014) ideas of extreme sports.

Sensation seeking is defined as "the need for varied, novel, and complex sensations and experiences and the willingness to take physical, social, legal and financial risks for the sake of such experiences" (Zuckerman, 2009 , p. 455). A person with a high need for sensation seeking is either underestimating the risk, or just takes the risk as a reward, which is felt during the experience. On the other hand, low sensation seekers try to avoid taking risks and many researchers discovered the same: Athletes of high-risk sports have a higher need for stimuli (sensation seeking) than others (Jack \& Ronan, 1998; Kerr, 1991; Rossi \& Cereatti, 1993; Wagner \& Houlihan, 1994).

Castanier, Le Scanff, and Woodman (2010) state that participation in high-risk activities can be a strategy to redirect attention away from their low self-esteem. Breivik (1999) found higher results in thrill and adventure and experience seeking factor in alpinists, extreme kayakers and sky divers, but other authors found that 
athletes of high-risk sports are also ready to risk in the social field (Kajtna, 2013). Studies show that participating in high-risk sports is highly correlated with the need for stimuli - sensation seeking (Guszkowska \& Bołdak, 2010).

The need for thrill and adventure was found as the most important reason why people do high-risk sports (Rowland, Franken, \& Harrison, 1986). However, Barlow, Woodman, and Hardly (2013) pointed out that high-risk sports athletes are not alike - skydivers enjoy free fall, meanwhile alpinists enjoy having everything controlled (feelings and actions) when they approach the summit. Guszkowska and Bołdak (2010) suggest that we should not put all the high-risk sports athletes in the same basket - these kind of athletes are just not the same and we should consider every high-risk sport discipline separately. For instance, Monasterio, Alamri, and Mei-Dan (2014) conducted research about personality traits on a sample of alpinists and rock climbers. They found out that they are more carefree, relaxed, bold and brave than the general population.

It has also been pointed out that people who participate in individual sports have a slight tendency to emotional instability and impulsivity (Tohanean \& Chicomban, 2010) and some authors went further to look for emotional characteristics of athletes. Barlow et al. (2015) studied high-risk sports athletes and found that alexythimia was associated with taking further risk in sports, as taking part in high-risk activities provides easily identifiable emotions, as they are so much more intense. On the other hand, Castanier et al. (2010) state that people enter such activities in order to divert their attention from what is causing them negative emotions, as a strategy to escape the negative emotions.

A lot of studies (Barlow et al., 2013; Guszkowska \& Bołdak, 2010) found out that we cannot equate athletes of different high-risk activities. Every high-risk sport is different and it demands different competencies of its participants. Castanier et al. (2010) pointed out that doing a high-risk physical activity is because it can give you psychological and also physical rewards, in addition high-risk sport can serve as an escape when a person is facing negative influences from society.

Personality represents a relatively consistent and unique sum of psychological, cognitive and physical characteristics of an individual (Musek, 1993). Theory of personality is a scientific explanation, which is trying to link the knowledge about personality in comprehensive system. There are many different approaches (theories) to explain personality: structural, psychoanalytic, behavioural, humanistic, social and cognitive ones (Musek, 1993).

McCrae and Costa (1997) determined The Big Five personality model which is based on a factorial approach (and not lexical) of personality questionnaires. The Big Five factors were named: neuroticism, extraversion, agreeableness, conscientiousness and openness for experience (Kajtna, 2013). The Fivefactor Model of Personality (The Big Five) is one of the most important events in studying personality. Even though it complements the biological genetic approach, it is not generally accepted. Based on The Big Five model, Big Five Questionnaire (BFQ) and Big Five Observer (BFO) were made in Italy (Caprara, Barbaranelli, Borgogni, Bucik, \& Boben, 1997).

Tok (2011) has made interesting research on highrisk sports athletes and people who do not participate in such activities, using BFQ. There were many significant findings: high-risk sports athletes were more open in openness for experience, extraversion was found as an important factor, correlated with high-risk sports, people who are more neurotic are easily stimulated with stimuli whose rewards are pleasant sensations and experiences, high-risk sports athletes had lower result in neuroticism and conscientiousness.

People who do sports are known to be more extraverted, aggressive, emotionally stable and less anxious then others. They are also believed to have a higher need for stimuli and stronger need for productivity (Tušak \& Burnik, 2001). People who participate in high-risk sports are seeking joy, pleasure, themselves, their personality and also personality confirmation, which is repressed by the monotony of the working day. They do not respect norms and do socially needed work just with the intention to satisfy their needs later. We are talking about their lifestyle, way of thinking, their idea of freedom and much more. Society often refers to high-risk sports athletes as unreasonable savages or suicidal madmen who do not respect their lives (Kajtna, 2013).

Zuckerman (1994) had done some studies about correlations between sensation seeking and personality traits using SSS and BFQ. ES factor is the one correlating the most with openness; also general factor of SSS is correlating with extraversion (highly), openness, conscientiousness (low) and negatively with agreeableness. After, he was able to define an individual with a high need for stimulation - a high sensation seeker is open to new experiences (especially to those referring to values, actions and fantasy), active and impulsive, needs the excitement, experiences and expresses positive emotions and anger. Markič (1990) found out that alpinists are more introverted, individualists, more independent, with totally different moral codes, more serious and calm than the general population. On the other hand Tušak and Burnik (2001) claim the opposite: alpinists are less honest and neurotic, more extraverted and sociable than the general population (Kajtna, 
2013). Ski jumpers seem to be, according to Tušak and Bednarik (2001), more honest, sociable, dominant and emotionally stable than the general population. Also another study on divers showed higher extraversion in favour of high-risk sports athletes (Tušak, Burnik, \& Robič, 2001). There is also one important finding about gender and sports with high levels of risk - there are no differences between female and male athletes in terms of personality traits (Burnik, Jug, \& Kajtna, 2008). Kajtna (2013) points out some statements about high-risk sports athletes - they are high in conscientiousness, emotional stability and extraversion, moderately open and have a higher general need for stimuli than athletes and non-athletes.

There seems to be a research gap in systematic comparison of high-risk sports athletes and the general population, that is physically active, people, who only do sports recreationally - the purpose of this research was to compare the personality and sensation seeking of high-risk sports athletes and recreational athletes. There is also some debate between authors on whether we should use SSS for V or VI, as one measures just the opinions of subjects and the other discriminates between the subjects' purpose to engage in activity and his or her actual participation in activity. We thus also wanted to compare the results obtained on these two versions of SSS and to see whether subjects' purpose and actual participation correlate.

\section{Methods}

\section{Participants}

Participants included 127 Slovenian males. Seventysix were active high-risk sport individuals, performing in activities such as sky diving, alpinism, diving, downhill skiing and ski jumping. Their average age was 23.79 years. The remaining participants (51) were recreational athletes with an average age 30.95 , who do sports such as jogging, playing basketball, soccer and other recreational physical activities. The differences in the age were not significant $(p=.17)$. All of the participants had university education or higher, the differences in educational level in both subsamples were not significant $(p=.79)$ and all participants were employed, $78.37 \%$ of them were employed in the public sector.

\section{Instruments}

Big Five Questionnaire (BFQ) - the Slovene translation (Caprara et al., 1997). This questionnaire has 132 items and is designed to assess the Big Five personality traits: energy, conscientiousness, emotional stability, openness and agreeableness, as well as 10 sub dimensions. At every sub dimension half of the statements are designed in positive, the other half in a negative way according to the personality trait measured.

Sensation Seeking Scale (SSS), forms V and VI (Zuckerman, 1994) - the Slovene translation (Lamovec, 1988).

SSS $-\mathbf{V}$ is a questionnaire consisted of 40 pairs of statements. Each time, the subject has to choose the one that best represents him or her. Factors of SSS - V: - Thrill and adventure seeking factor (TAS) encompasses the desire for participating in unusual physical activities such as sky diving, diving, alpinism, car racing and the like.

- Experience seeking factor (ES) refers to seeking out unusual sensual and/or mental experience and to the unconventionality of someone's lifestyle. It is shown by need to wear extraordinary clothes, to shock others, by having an interest in new, different places and people, also using drugs.

- Disinhibition factor (DIS) refers to seeking for pleasure, mainly a sexual. It is marked by desire to engage in wild parties, attended by attractive and often people influenced by alcohol that give in to uninhibited sensuality.

- Boredom susceptibility factor (BS) includes the rejection of repetitive events and routine, same places and faces and also the rejection of predictable and boring individuals. BS is also shown in the tendency to change work places, to buy new products, to try new and unusual food, and so on.

- General factor marks the desire for an exciting life, which is full of adventure, a tendency to want to experience everything possible. It is demonstrated as an interest in unusual and high-risk sports, for unplanned travels and experiencing extraordinary sensations with the aid of drug use, hypnosis, etc. General factor is also shown as desire to associate with unpredictable, dynamic and emotional people.

SSS - VI is a similar questionnaire, but consists of two parts, each has 64 statements. Parts are the same, the only difference is that statements in the first part ask about experience, but in the second, statements refer to intention to do the act in future. Although, there are 7 different statements in experience part of the questionnaire. Activities in those statements specify infrequency (lie). For instance, it is hard to be that someone has conquered Mount Everest. A person who obtains high results, more specifically, a value over 7 , is probably misunderstanding the test, acting recklessly and negatively toward the test. Factors of SSS - VI: Experience:

- Thrill and adventure seeking factor (TASEXP) encompasses the experience with participating in 
unusual physical activities such as sky diving, diving, alpinism, car racing and the like.

- Disinhibition factor (DISEXP) refers to seeking pleasure, mainly sexual. It includes experience with engaging in wild parties, attended by attractive and often people influenced by alcohol that give in to uninhibited sensuality.

Intention:

- Thrill and adventure seeking factor (TASINT) encompasses the intention to participate in unusual physical activities such as sky diving, diving, alpinism, car racing and the like.

- Disinhibition factor (DISINT) refers to intention to engage in wild parties, attended by attractive and often alcohol influenced people that give in to uninhibited sensuality.

\section{Procedure}

The application of the questionnaires was carried out on participants from 2001 to 2003. We obtained data on high risk sports athletes through the National organizations (cycling, mountaineering, etc.) and contacted the participants through e-mail. Those who agreed to participate then answered the questionnaires, the testing was anonymous. Data were analysed using the IBM SPSS Statistics statistical program (Version 20; IBM, Armonk, NY, USA), graphs and tables were made with Microsoft Office Excel (Version 2013; Microsoft, Redmond, WA, USA). Variability among groups was analysed using $t$-test and analysis of variance. Correlations were analysed with Pearson's correlation coefficient. The distribution of the data was normal, skewness and kurtosis parameters were all within range of normal distribution and Kolmogorov-Smirnov tests were 16 or more in significance. Statistical significance was used at the .05 level. The research was approved by a review board of the Faculty of Sport, University of Ljubljana, and the participants provided informed consent for participation in the study.

\section{Results}

There are two statistically significant variabilities between the two groups in which recreational athletes received higher results - agreeableness and openness.

Results in Table 1 show that recreational athletes are more agreeable and open when compared to recreational athletes.

In Table 2 we can see high-risk sports participants' and recreational athletes' values of factors in sensation seeking scales, forms $\mathrm{V}$ and VI, which we used to analyse differences in sensation seeking between groups.
Table 1

Differences between high-risk sports athletes and recreational athletes in personality

\begin{tabular}{lrrrr}
\hline Category & $M$ & $S D$ & \multicolumn{1}{c}{$t$} & \multicolumn{1}{c}{$p$} \\
\hline Energy & & & & \\
$\quad$ High-risk & 80.14 & 7.94 & -1.04 & .30 \\
$\quad$ Recreational & 81.82 & 10.27 & & \\
Agreeableness & & & & \\
$\quad$ High-risk & 80.36 & 8.98 & -2.31 & .02 \\
$\quad$ Recreational & 83.92 & 7.45 & & \\
Conscientiousness & & & & \\
$\quad$ High-risk & 79.68 & 9.39 & -1.81 & .07 \\
$\quad$ Recreational & 82.80 & 9.39 & & \\
Emotional stability & & & & \\
$\quad$ High-risk & 76.75 & 10.10 & -0.64 & .52 \\
$\quad$ Recreational & 77.98 & 11.30 & & \\
Openness & & & & \\
$\quad$ High-risk & 79.20 & 9.92 & -2.17 & .03 \\
$\quad$ Recreational & 83.20 & 10.34 & & \\
\hline
\end{tabular}

Table 2

Differences between high-risk sports athletes and recreational athletes in sensation seeking

\begin{tabular}{|c|c|c|c|c|}
\hline Factor & $M$ & $S D$ & $t$ & $p$ \\
\hline \multicolumn{5}{|c|}{ Thrill and adventure seeking (V) } \\
\hline High-risk & 7.83 & 1.75 & -0.92 & .36 \\
\hline Recreational & 8.14 & 2.01 & & \\
\hline \multicolumn{5}{|c|}{ Experience seeking $(\mathrm{V})$} \\
\hline High-risk & 6.32 & 2.09 & 1.09 & .28 \\
\hline Recreational & 5.88 & 2.35 & & \\
\hline \multicolumn{5}{|c|}{ Disinhibition (V) } \\
\hline High-risk & 6.82 & 2.00 & 0.95 & .35 \\
\hline Recreational & 6.47 & 2.04 & & \\
\hline \multicolumn{5}{|c|}{ Boredom susceptibility (V) } \\
\hline High-risk & 3.88 & 1.85 & 1.78 & .08 \\
\hline Recreational & 3.31 & 1.63 & & \\
\hline \multicolumn{5}{|c|}{ General factor $(\mathrm{V})$} \\
\hline High-risk & 24.84 & 5.63 & 1.02 & .31 \\
\hline Recreational & 23.80 & 5.68 & & \\
\hline \multicolumn{5}{|l|}{ Infrequency (VI) } \\
\hline High-risk & 7.22 & 1.03 & -1.77 & .08 \\
\hline Recreational & 7.57 & 0.92 & & \\
\hline \multicolumn{5}{|c|}{ Thrill and adventure seeking - experience (VI) } \\
\hline High-risk & 28.87 & 4.37 & 0.24 & .81 \\
\hline Recreational & 28.65 & 4.77 & & \\
\hline \multicolumn{5}{|c|}{ Disinhibition - experience (VI) } \\
\hline High-risk & 92.00 & 15.36 & 1.33 & .19 \\
\hline Recreational & 87.96 & 14.44 & & \\
\hline \multicolumn{5}{|c|}{ Thrill and adventure seeking - intention (VI) } \\
\hline High-risk & 50.91 & 7.90 & -0.50 & .62 \\
\hline Recreational & 51.78 & 9.06 & & \\
\hline \multicolumn{5}{|c|}{ Disinhibition - intention (VI) } \\
\hline High-risk & 93.80 & 11.78 & 1.44 & .15 \\
\hline Recreational & 89.73 & 15.58 & & \\
\hline
\end{tabular}

Note. $\quad \mathrm{V}=$ Sensation Seeking Scale Form V; VI = Sensation Seeking Scale Form VI. 


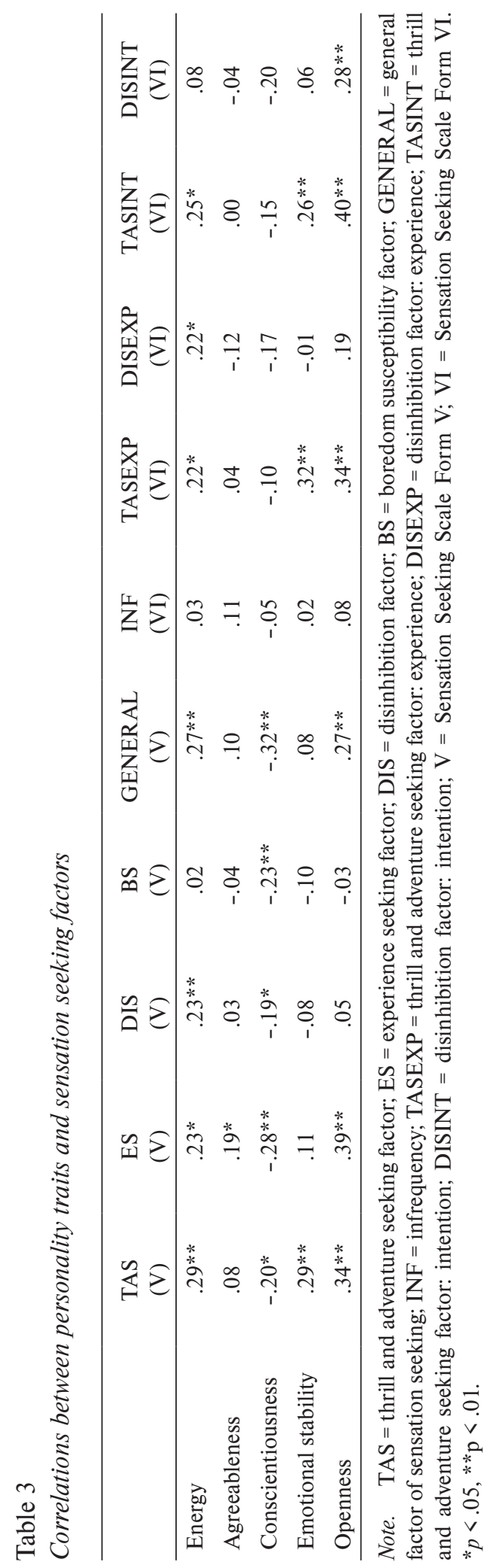

Our results in Table 3 show that there are correlations between factors of sensation seeking scales and personality traits. Some of them were already approved by Zuckerman (1994). We can also confirm some tendencies to statistically significant correlations between variables, but we will focus only on correlations, which are statistically significant.
We checked for correlations between intention and experience in the SSS form VI and found high correlations for both factors: .62 for Thrill and adventure seeking and .67 for Disinhibition.

\section{Discussion}

Our results show that there are differences in personality and sensation seeking between high-risk sports athletes and recreational athletes. These results are unexpected, especially finding regarding openness. Studies indicate that openness and agreeableness are higher in high-risk sports participants (Kajtna, 2013). Although some studies have shown similar results, Kajtna (2013) says that recreational athletes are more open then high-risk sports athletes. We can confirm findings of Tok (2011) that recreational athletes have higher results in conscientiousness. On the other hand, some studies indicated different findings (Kajtna, 2013).

With these results we can say that people who participate in high-risk sports are more selfish and less cooperative, friendly, generous and empathic than recreational athletes - and also according to other authors this is how people who have to perform in extreme conditions should be (Barrett \& Martin, 2014). This description is similar to the description of Castanier et al. (2010), who indicated that people with negative affectivity more frequently enter high-risk sports and findings of Barlow et al. (2015), who indicate that alexithymia could lead people to seek out high-risk environments.

Also, athletes who do high-risk sports are lower in ability to understand and support others; they are less open and have less trust in other people. The same thing is happening with openness where recreational athletes received higher results. High-risk sports' athletes appear to have less interest in new experiences and are more small-minded than recreational athletes. We report that people who do high-risk sports do not have such a positive attitude to novelties and new or different values, lifestyles, cultures and customs.

Finally, we also can report that high-risk sports athletes are less circumspect, accurate, caring and persistent than people who do more conventional sports. In addition, they are supposed to have less order and to be less reliable.

Higher results in boredom susceptibility factor could be easily understood. Athletes who participate in high-risk sports are supposed to refuse repetitive events, routine, the same places and faces, predictable and boring people - a similar description can be found in Rinehart's (2000) writing on sports, which stem from defying existing social norms. People who receive high results in boredom susceptibility are more prone to 
change employment, buy new products and try new and unusual food (Zuckerman, 1994). It is easy to explain that: high-risk sports are unpredictable activities and they change all the time. No parachute jump is the same as the one before; no mountain climb is the same, due to the fact that these high-risk activities are going on in nature, which is unpredictable. Kajtna (2013), Breivik (1999) and Grosek (2010) claim that there are no differences in boredom susceptibility between high-risk sports athletes and recreational athletes.

When looking at correlations, we will firstly talk about openness. This personality trait is a general appreciation for art, emotion, adventure, unusual ideas, imagination, curiosity, and variety of experience. As showed, our results indicate a correlation between openness and TAS factor, as also with ES factor of sensation seeking scale. McCrae (1987, in Zuckerman, 1994) discovered the same with addition of correlation between openness and DIS factor - we were not able to confirm that. Also Zuckerman (1994) reported that there is an important correlation between ES and openness. We did not find a correlation between GENERAL factor of sensation seeking and openness.

We can confirm that a person, who has a tendency to seek out unusual sensual or mental experiences and to the unconventionality of one's lifestyle, is more open, which is marked by being more educated, informed, having high interest in new experiences and being open to knowing new people. In addition, a more open person is someone who has a higher desire for participating in unusual physical activities, such as skydiving, alpinism, diving and the like. High-risk sports surely represent unusual physical activities. If a person were doing such activities, we would have expected that has interest in new experiences. Also, during performing high-risk sports people feel unusual sensual or mental experience that could not be felt during everyday events. Our findings about correlations with openness are understandable, as high-risk sports athletes should seek out novel experiences and sensations, as high-risk sports represent unusual physical activities, which constantly offer experiencing unusual sensations, new situations and novelties. As with form V, the same results were shown with analysing form VI of SSS. We can confirm a correlation between both thrill and adventure seeking - experience and intention. People who already did or have the intention to experience unusual and dangerous physical activities - high-risk sports, are more open.

The other thing we must discuss is an important correlation between conscientiousness and general factor of SSS. There is a negative correlation between these two variables. Our conclusion is that people who have a desire for an exciting life, full of adventure, and want to experience all possibilities and are interested in unusual and exciting sports, are less circumspect, accurate, caring and persistent. Also, they are believed to have less order and to be less reliable - social belief says that highrisk sports athletes are reckless and less circumspect, who do not care about people around them, and they just live for a sensation which can be felt with doing unusual and dangerous activities. Our results are consistent with Zuckerman's (1994) finding that there is a low, but important negative correlation between general factor of SSS and conscientiousness.

There is also a correlation between emotional stability and experience in thrill and adventure seeking when it comes to SSS form VI. Emotionally stable people are presented as individuals who are less easily upset and are less emotionally reactive. They tend to be calm, emotionally stable, and free from persistent negative feelings. High-risk sports athletes participate in unusual physical activities and are more emotionally stable. When participating in a high-risk activity, where even your life is at risk, athletes have to stay calm and emotionally stable, so that they are able to react quickly and avoid irreparable consequences. Correlations we found between experience in thrill and adventure seeking and emotional stability were expected. What is important is the fact that individuals who already experienced unusual physical activities are emotionally stable. At any rate, we also can report that individuals who just have intent to do unusual physical activity achieve higher results in emotional stability.

We found high correlations between intention and experience on both factors of SSS form VI - thrill and adventure seeking and disinhibition, which was expected and logical. We found slightly higher a statistically significant correlation disinhibition factor of sensation seeking. People who are more experienced in seeking pleasure with engaging in wild parties and having fun with happy and sexually attractive people, have also more intention to do those things in future. The same is with thrill and adventure seeking: the more that person has experience in practicing unusual and dangerous physical activities, the higher are his intentions to try high-risk, unusual and dangerous activity, which have yet not been experienced by that person.

The findings stem from a fairly large number of highrisk sports athletes, who participate in their sport on a high level, which means that the results are generalizable to some extent, although we believe that we might need to collect a more compatible group of recreational athletes to say that we can truly generalize the findings. It would also be interesting to study emotional aspects of high-risk sports athletes more deeply, as emotional aspects emerged in this study as one of the key factors to influence high-risk sports participation. 


\section{Conclusions}

Our study confirms preliminary findings that there are differences in personality and sensation seeking between high risk sports athletes and recreational athletes. The latter were more open, which is unexpected due to the high-risk, new and unusual activities high-risk sports athletes are participating in. The same occurred with agreeableness, where high-risk sports athletes also scored lower, people who do high-risk sports are believed to not have so positive attitude to novelties.

Through correlations between personality dimensions and sensation seeking factors we found that people, who are higher in sensation seeking, are more open - they have high interest in new experience and a higher desire for participating in unusual physical activities. Higher sensation seeking also correlated with higher emotional stability. When it comes to differences between high-risk sports athletes and recreational athletes, we found important findings, especially about openness, which should be an important subject of future researches in high-risk sports field.

\section{Conflict of interest}

There were no conflicts of interest.

\section{References}

Barlow, M., Woodman, T., Chapman, C., Milton, M., Stone, D., Dodds, T., \& Allen, B. (2015). Who takes risks in highrisk sports? The role of alexithymia. Journal of Sport \& Exercise Psychology, 37, 83-96.

Barlow, M., Woodman, T., \& Hardly, L. (2013). Great expectations: Different high-risk activities satisfy different motives. Journal of Personality and Social Psychology, 105, 458-475.

Barrett, E., \& Martin, P. (2014). Extreme: Why some people thrive at the limits. Oxford, United Kingdom: Oxford University Press.

Breivik, G. (1999). Sensation seeking in sport. Oslo, Norway: Norwegian School of Sport Sciences.

Burnik, S., Jug, S., \& Kajtna, T. (2008). Sensation seeking in Slovenian female and male mountain climbers. Acta Universitatis Palackianae Olomucensis. Gymnica, 38(3), 15-19.

Caprara, G. V., Barbaranelli, C., Borgogni, L., Bucik, V., \& Boben, D. (1997). Model „velikih pet» - pripomočki za merjenje strukture osebnosti [The Big-five model - instruments for measuring personality structure]. Ljubljana, Slovenia: Produktivnost d.o.o.

Castanier, C., Le Scanff, C., \& Woodman, T. (2010). Beyond sensation seeking: Affect regulation as a framework for predicting risk-taking behaviors in high-risk sport. Journal of Sport \& Exercise Psychology, 32, 731-738.

Grosek, A. (2010). Osebnost in potreba po dražljajih pri alpinistih, vrhunskih športnikih in rekreativcih (Diplomsko delo)
[Personality and sensation-seeking in mountain climbers, top athletes and recreational athletes (Graduate thesis)]. University of Ljubljana, Faculty of Sport, Ljubljana, Slovenia.

Guszkowska, M., \& Bołdak, A. (2010). Sensation seeking in males involved in recreational high risk sports. Biology of Sport, 27, 157-162.

Jack, S. J., \& Ronan, K. R. (1998). Sensation seeking among high- and low- risk sports participants. Personality and Individual Differences, 25, 1063-1083.

Kajtna, T. (2013). Nekateri psihološki vidiki rizičnih športov (Znanstvena monografija) [Some psychological aspects of high-risk sports (Scientific monography)]. Ljubljana, Slovenia: University of Ljubljana.

Kerr, J. H. (1991). Arousal-seeking in risk sports participants. Personality and Individual Differences, 12, 613-616.

Lamovec, T. (1988). Priročnik za psihologijo motivacije in emocij [Manual for psychology of motivation and emotions]. Ljubljana, Slovenia: University of Ljubljana.

Markič, P. (1990). Osebnostne lastnosti vrhunskih alpinistov in plezalcev [Personality traits of mountain climbers and sports climbers]. In V. Pogačnik (Ed.), Študije Cattellovih testov 16PF (pp. 21-29). Kranj, Slovenia: Self-published.

McCrae, R. R., \& Costa, P. T. Jr. (1997). Conceptions and correlates of openness to experience. In R. Hogan, J. A. Johnson, \& S. Briggs (Eds.), Handbook of personality psychology (pp. 825-847). San Diego, CA: Academic Press.

Monasterio, E., Alamri, Y. A., \& Mei-Dan, O. (2014). Personality characteristics in a population of mountain climbers. Wilderness \& Environmental Medicine, 25, 214-219.

Musek, J. (1993). Osebnost pod drobnogledom [Personality investigated]. Maribor, Slovenia: Obzorja.

Rinehart, R. (2000). Emerging/arriving sport: Alternatives to formal sports. In J. Coakley \& E. Dunning (Eds.), Handbook of sports studies (pp. 504-519). London, United Kingdom: Sage Publications.

Rossi, B., \& Cereatti, L. (1993). The sensation seeking in mountain athletes as assessed by Zuckerman's Sensation Seeking Scale. International Journal of Sport Psychology, 24, 417-431.

Rowland, G. L., Franken, R. E., \& Harrison, K. (1986). Sensation seeking and participation in sporting activities. Journal of Sport Psychology, 8, 212-220.

Thorpe, H., \& Wheaton, B. (2013). Dissecting action sports studies - past, present, and beyond. London, United Kingdom: Blackwell Publishing.

Tohanean, D. I., \& Chicomban, M. (2010). Personality and performance sport. Ovidius University Annals, Series Physical Education and Sport/Science, Movement and Health, 2(Suppl.), 609-613.

Tok, S. (2011). The big five personality traits and high-risk sport participation. Social Behavior and Personality, 39, 1105-1112.

Tušak, M., \& Bednarik, J. (2001). Osebnost športnika [Personality of an athlete]. In J. Bednarik \& M. Tušak (Eds.), Šport, motivacija in osebnost (pp. 180-187). Ljubljana, Slovenia: University of Ljubljana.

Tušak, M., \& Burnik, S. (2001). Osebnost alpinistov [Personality of mountain climbers]. In J. Bednarik \& M. Tušak (Eds.), Šport, motivacija in osebnost (pp. 201-218). Ljubljana, Slovenia: University of Ljubljana. 
Tušak, M., Burnik, S., \& Robič, B. (2001). Osebnostne lastnosti potapljačev [Personality traits of scuba divers]. In J. Bednarik \& M. Tušak (Eds.), Šport, motivacija in osebnost (pp. 188-200). Ljubljana, Slovenia: University of Ljubljana. Wagner, A. M., \& Houlihan, D. D. (1994). Sensation seeking and trait anxiety in hang-glider pilots and golfers. Personality and Individual Differences, 16, 975-977.
Zuckerman, M. (1994). Behavioral expressions and biosocial bases of sensation seeking. Cambridge, United Kingdom: Cambridge University Press.

Zuckerman, M. (2009). Sensation seeking. In M. R. Leary \& R. H. Hoyle (Eds.), Handbook of individual differences in social behavior (pp. 455-465). New York, NY: The Guildford Press. 